\title{
Sistem Pengalokasian Dinamik VLAN Dalam Mendukung Proses Belajar Terdistribusi
}

\author{
Oleh \\ Ferrianto Gozali dan Billion Lo \\ Jurusan Teknik Elektro, Fakultas Teknologi Industri, Universitas Trisakti, Jakarta \\ ( ferrianto@trisakti.ac.id, billion@std.trisakti.ac.id )
}

\begin{abstract}
ABSTRAK
Seiring perkembangan pendidikan, penggunaan ICT sangatlah besar dalam proses perkembangan tersebut. Dengan penggunaan ICT ini, memungkinkan distance learning diimplementasi dimana proses belajar mengajar tidak harus lagi berada dikelas seperti pada pendidikan yang konvensional. Dengan adanya distance learning dapat memecahkan masalah spasial baik dari ukuran ruangan terhadap jumlah murid dan keterbatasan untuk dapat hadir kedalam ruang perkuliahan. Karena itulah, Sistem Pengalokasian Virtual Local Area Network (VLAN) secara Dinamis dibutuhkan. Sistem ini merupakan sistem yang berbasis protokol Radius yang dapat membantu untuk mengotentikasi dan memindahkan client antar sub jaringan (VLAN) didalam jaringan internal suatu perkuliahan.

Perancangan sistem digunakan aplikasi berbasis open source. Pada perancangan sistem Dinamik VLAN ini, penulis menggunakan sistem otentikasi berdasarkan MAC-Address dari client yang akan dimapping kedalam VLAN yang akan dituju. MAC-Address dan VLAN yang akan dituju disimpan didalam database. Untuk skema jaringannya, server dan client akan terhubung menggunakan manageable switch.

Mekanisme kerja dari sistem pengalokasian VLAN secara dinamis ini terdiri dari 3 (tiga) tahap yaitu: tahap penerimaan request dari Network Access Server (NAS), pengecekan MAC-Address terhadap VLAN yang dituju dan persetujuan otentikasi dan otorisasi. Untuk mendukung proses pembelajaran jarak jauh, digunakan Web Conference dan aplikasi seperti file sharing pada jaringan VLAN tersebut.Untuk pengujian sistem tersebut, kita menggunakan applikasi Web Conference dengan cara membandingkan performa jaringan pada saat dengan dan tanpa sistem tersebut.

Dalam mengimplementasikan sistem ini, terbilang murah karena suatu perusahaan hanya membutuhkan sebuah server dengan Sistem Operasi yang gratis dan aplikasi yang gratis dan dapat diimplementasikan langsung ke dalam jaringan perusahaan tanpa perubahan topologi jaringan yang menyeluruh.Namun dalam sistem ini masih terdapat kekurangan, dimana sistem ini hanya dapat diaplikasikan dengan menggunakan Manageable Switch dan belum dapat digunakan untuk Wi-fi dan Unmanageable Switch.
\end{abstract}

Kata Kunci: Jaringan Komputer, Sistem Dinamik, VLAN, Radius.

\section{Pendahuluan}

Perkembangan ICT saat ini sangat membantu dalam perkembangan bidang pendidikan, terutama dalam proses belajar dan mengajar antara guru dan murid. Proses ini, terutama diluar negeri, sudah tidak terpaku lagi pada proses belajar dan mengajar yang konvensional, dimana guru dan murid melakukan tatap muka di ruang kelas. Proses belajar tersebut sudah mulai beralih ke bentuk distance learning dimana problem spasial yang biasa kita temui dapat dipecahkan, terutama pada keterbatasan ukuran kelas terhadap jumlah murid dan keterbatasan untuk dapat hadir di ruang kelas.Karena itulah, Sistem Pengalokasian Virtual Local Area Network (VLAN) secara Dinamis dibutuhkan.

Sistem ini merupakan sistem yang berbasis protokol Radius yang dapat membantu untuk mengotentikasi dan memindahkan client antar sub jaringan (VLAN) didalam jaringan internal suatu 
perusahaan tanpa harus adanya seorang technical support untuk mengkonfigurasi jaringan baik router maupun switch secara manual.

Tulisan ini membahas apa itu VLAN, Radius, bagaimana pengalokasian VLAN secara dinamis, apa perubahan perlu yang dilakukan pada jaringan yang belum mengimplementasi sistem tersebut, dan pengetesan performa sistem tersebut dan perbandingannya dengan jaringan sebelum diimplementasi sistem tersebut.

Pada pengembangan sistem tersebut digunakan perangkat lunak Open Source sifatnya gratis dan sisi ketahanan dari sistem bisa dibilang cukup handal.Perangkat lunak yang digunakan adalah FreeRadius, MySQL server untuk sistem pengalokasian VLAN dinamis.

\section{Konsep dasar VLAN}

Virtual Local Area Network atau dikenal dengan VLAN merupakan fungsi logik dari sebuah perangkat jaringan, dimana fungsi logik ini mampu membagi jaringan LAN yang secara fisik tersambung dalam suatu jaringan global ke dalam beberapa jaringan yang bersifat virtual. Dengan menggunakan VLAN maka administrator jaringan dapat lebih mudah mengelompokkan workstation didalam jaringan berdasarkan fungsinya tanpa dibatasi oleh lokasi fisik workstation tersebut.Berbagai kelebihan VLANjika dibandingkan dengan LAN biasa, antara lain:

- Broadcast control, dimana VLAN mampu membatasi broadcast network dari masing-masing grup;

- Security, dimana VLAN membentengi akses ke sebuah grup dari group VLAN lain atau akses dari luar jaringan;

- Performance, dimana pengelompokkan secara grup logik ini memberikan jalur data yangbersifat dedicated untuk tiap-tiap grup, sehingga secara otomatis masing-masing grup akan mendapat kinerja jalur data yang optimal;

- Management, prinsip logik pada VLAN memberikan kemudahan seorang user dari suatu grup VLAN untukberpindah lokasi tanpa perlu mengganti koneksi/sambungan ke switch, dan administrator dapat dengan mudah mengubah keanggotaan suatu grup VLAN melalui aplikasi jaringan tanpa harus mengubah jaringan secara fisik.

Keanggotaan suatu workstation pada VLAN dapat dibedakan dalam dua kelompok yaitu yang bersifat statis dan bersifat dinamis.VLAN Statis merupakan cara umum dalam mengembangkan VLAN, dan sekaligus merupakan cara yang paling aman. Port pada switch bertugas untuk mempertahankan konektifitas pada VLAN secara statis. Pada implementasi ini administrator secara manual mengubah penugasan atau keanggotaan dari port tersebut. Keanggotaan VLAN jenis ini, umumnya digunakan untuk jaringan komputer yang sederhana dan jumlah workstation yang terhubung sifatnya terbatas,

Untuk melakukan komunikasi antar perangkat jaringan atau komputer menggunakan VLAN didalam sebuah jaringan global, maka dibutuhkan penanda pada paketdata yang dikirim agar tidak tersebar ke VLAN lainnya. Penanda ini disebut Frame Tagging (IEEE 802.1q) seperti terlihat pada gambar.1. Pada header dari paket data ditambah tag sepanjang 2 byte, yang berisi informasi VLAN ID dan Prioritas dari data tersebut. 


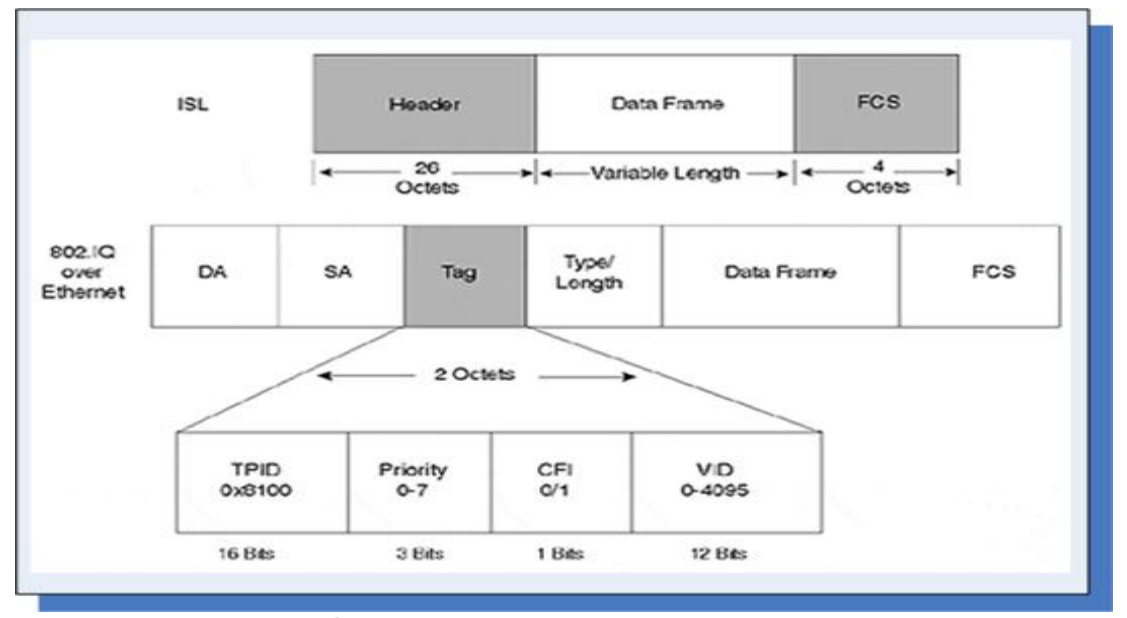

Gambar.1. VLAN Frame Tagging

VLAN dinamis, merupakan suatu pengembangan lanjut dari VLAN Statis dimana digunakan suatu aplikasi yang berfungsi untuk menentukan VLAN dari sebuah titik atau node secara otomatis. Dengan menggunakan aplikasi manajemen yang intelligenttersebut, maka dapat dibuat penugasan VLAN berdasarkan alamat-alamat perangkat keras (MAC Address), protocol-protocol, atau bahkan aplikasiaplikasi, untuk menciptakan VLAN-VLAN dinamis. Keanggotan VLAN jenis ini umumnya digunakan untuk jaringan komputer yang kompleks, komputer maupun switch yang terhubung didalamnya banyak dan pergerakan user yang dinamik.

\section{Remote Authentication Dial In User Service (RADIUS)}

Remote Authentication Dial In User Service(RADIUS) adalah protokol jaringan yang mengatur proses manajemen otentikasi, otorisasi dan akuntasi (AAA) yang tersentralisasi dalam memberikan akses pada komputer pengguna untuk menggunakan layanan jaringan tertentu. Tiga fungsi utama dari RADIUS adalah:

- Authentication, untuk mengotentikasi pengguna atau perangkat sebelum memberikan mereka akses ke jaringan,

- Authorization, untuk memberikan hak kepada pengguna atau perangkat untuk mengakses jaringan tertentu,

- Accounting, untuk menghitung penggunaan layanan dari pengguna atau perangkat tersebut.

Dalam berkomunikasi, Radius menggunakan UDP dengan port 1812 untuk proses akuntansi dan port 1813 untuk proses otentikasi dari Radius. Ketentuan ini didasarkan pada ketentuan yang ditetapkan oleh Internet Assigned Number Authority (IANA) walaupun sebelum ketentuan tersebut banyak yang menggunakan port 1645 dan 1646 (akuntansi dan otentikasi) menjadi standar port yang digunakan oleh banyak client / server Radius .

RADIUS menyediakan tiga metode otentikasi yang berbeda yaitu Password Authentication Protocol (PAP), Challenge-Handshake Authentication Protocol (CHAP) dan Extensible Authentication Protocol (EAP).Dalam uji coba ini digunakan metoda CHAP [RFC 1994].CHAP secara berkala melakukan verifikasi identitas dari client dengan menggunakan metode three-way handshake. Mekanisme otentikasi dari CHAP dapat dilihat pada Gambar 2. 


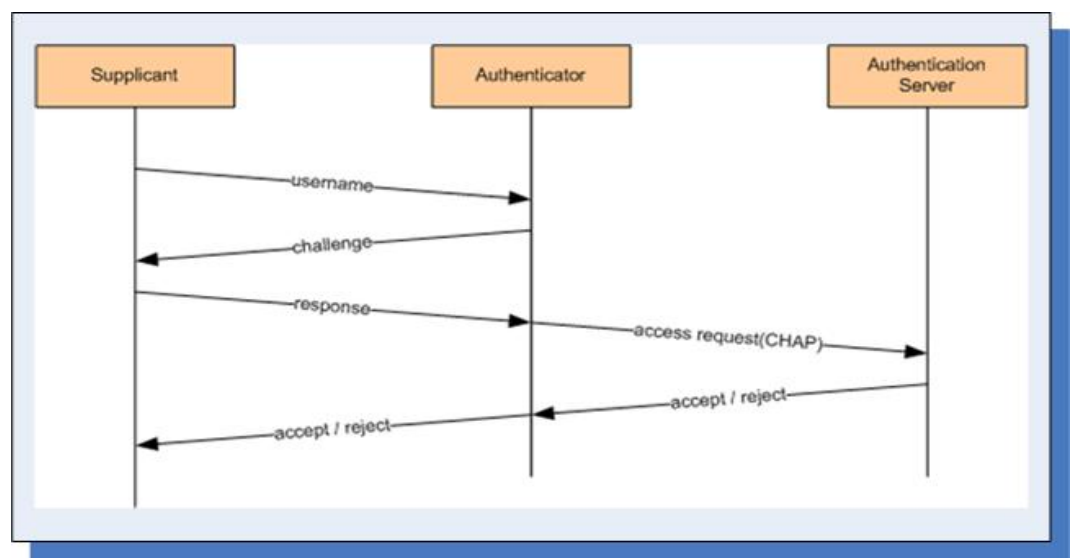

Gambar.2. Meknisme Otentkasi CHAP

Pertama-tama client sebagai Suplicant mengirimkan username kepada Authenticator, Authenticator membalas dengan memberikan challenge kepada pengguna. Pengguna akan memberikan kembali informasi berikutnya yang dibutuhkan oleh Authenticator untuk berkomunikasi dengan Radius server yang berfungsi sebagai Authentication Server, yang mengakibatkan terjadinya akses request (CHAP) yang dikirimkan oleh Authenticator ke Server Radius. Server Radius akan memberikan response, apakah akses tersebut diterima atau ditolak kepada Authenticator, untuk kemudian dilanjutkan kepada client.

\section{IMPLEMENTASI SISTEM}

Topologi yang digunakan dalam Implementasi sistem pengalokasian dinamik VLAN dapat dilihat pada gambar 3 .

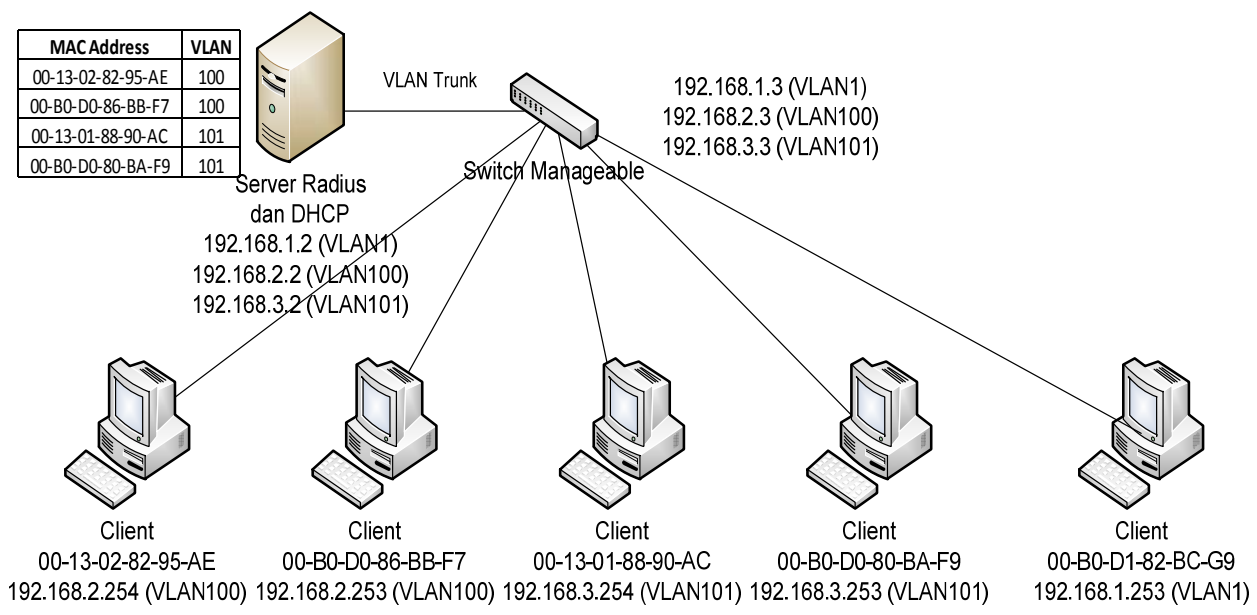

Gambar 3.Topologi global jaringan dari sistem Dinamik VLAN.

Dalam implementasi ini, Server Radius berfungsi sebagai Authentication Server dan Switch Manageable berfungsi sebagai Authenticator.Pada server radius terdapat database yang berisi MACAddress dari seluruh client yang dimapping terhadap VLAN yang dituju.Untuk uji coba digunakan 5 buah komputer, MAC-Address dari 4 buah komputer telah tercatat didatabase pada Server Radius dan MAC-Address dari 1 buah computer lainnya tidak tercatat didatabase. Dari percobaan ini, dapat 
dilihat bahwa 4 buah computer yang telah tercatat MAC-Addressnya mendapat VLAN 100 dan 101, sedangkan komputer lainnya hanya mendapat VLAN 1 (VLAN Guest) dimana pada policy di router, VLAN 1 tidak dapat terhubung ke VLAN 100 dan 101.Pada percobaan untuk mengukur utilisasi jaringan selanjutnya akan digunakan 4 buah computer yang mendapat VLAN 100 dan 101.

\section{IV.1. Proses Otentikasi dan Otorisasi}

Pada server Radius, terdapat database MySQL yang menyimpan data MAC-Address dari client dan VLAN yang akan diakses.Proses Otentikasi terjadi pada saat pertama kali client terhubung ke switch. Client akan mengirimkan data MAC-Address ke switch dan dilanjutkan ke server Radius, jika MAC-Address dari client tersebut terdapat didalam database, server Radius akan memerintahkan switch untuk memberikan otorisasi kepada client untuk masuk ke VLAN yang tersimpan di database. Client akan terhubung ke dalam VLAN yang dituju dan meminta IP ke DHCP server. Namun jika MACAddress dari client tidak tercatat di dalam database, maka client tersebut hanya akan mengakses VLAN untuk guest, dalam ini adalah VLAN 1.

\section{IV.2. Proses Implementasi pada topologi jaringan yang belum menggunakan VLAN}

Untuk melakukan implementasi sistem ini pada jaringan yang belum menggunakan VLAN, dimana seluruh karyawan dari divisi yang berbeda-beda terhubung satu sama lain dalam satu broadcast address, perlu ditambahkan sebuah server Radius, mengganti switch dengan manageable switch, mengganti router dengan router yang support VLAN namun topologi jaringan secara keseluruhan tidak perlu mengalami perubahan.

\section{IV.3. Pengukuran Perbandingan Utilisasi Jaringan tanpa dan dengan Sistem Dinamik VLAN}

Perbandingan performa dari jaringan dengan sistem dinamik VLAN dan tanpa sistem dinamik VLAN ini dilakukan dengan melihat faktor utilisasi jaringan.Pengukuran dilakukan dimana terdapat Server Web Confrence menggunakan sistem operasi Linux dan 4 buah client menggunakan sistem Windows XP. Proses pengukuran dilakukan dengan menghitung utilisasi jaringan rata-rata selama satu menit pada saat melakukan Web Confrence.

Topologi jaringan tanpa sistem Dinamik VLAN dapat dilihat pada Gambar.4 dan hasil pengukuran utilisasi jaringan dapat dilihat pada Tabel.1.

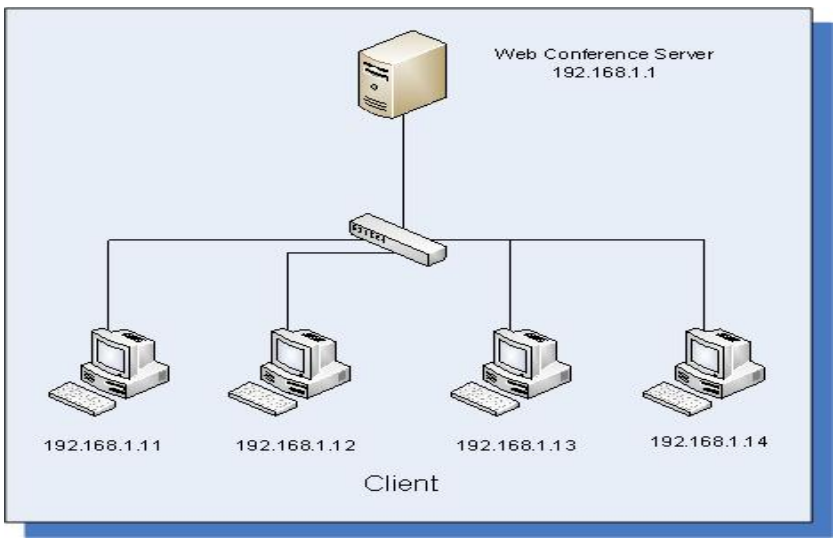

Gambar.4. Topologi jaringan tanpa sistem Dinamik VLAN 
Tabel.1. Hasil Pengukuran utilisasi jaringan Tanpa sistem Dinamik VLAN

\begin{tabular}{|c|c|c|c|c|c|}
\hline & \multicolumn{5}{|c|}{ 4 Client } \\
\cline { 2 - 6 } & $\begin{array}{c}\text { Web } \\
\text { Server }\end{array}$ & Client 1 & Client 2 & Client 3 & Client 4 \\
\hline $\begin{array}{c}\text { Utilisasi Rata- } \\
\text { Rata (bits/s) }\end{array}$ & $2,282,400$ & $740,636.46$ & $647,792.32$ & $673,450.82$ & 635,625 \\
\hline IP Address & 192.168 .1 .1 & 192.168 .1 .11 & 192.168 .1 .12 & 192.168 .1 .13 & 192.168 .1 .14 \\
\hline Durasi (menit) & - & $1: 00$ & $1: 00$ & $1: 00$ & $1: 00$ \\
\hline
\end{tabular}

Dari pengukuran diatas didapatkan utilitas rata-rata dari webserver yang digunakan untuk web conference sebesar 2,282 Mbps dan utilisasi rata-rata client sebesar $670 \mathrm{kbps}$.

Topologi jaringan dengan system dinamik VLAN dapat dilihat pada gambar.5.dan hasil pengukuran utilisasi jaringan dapat dilihat pada Tabel.2.

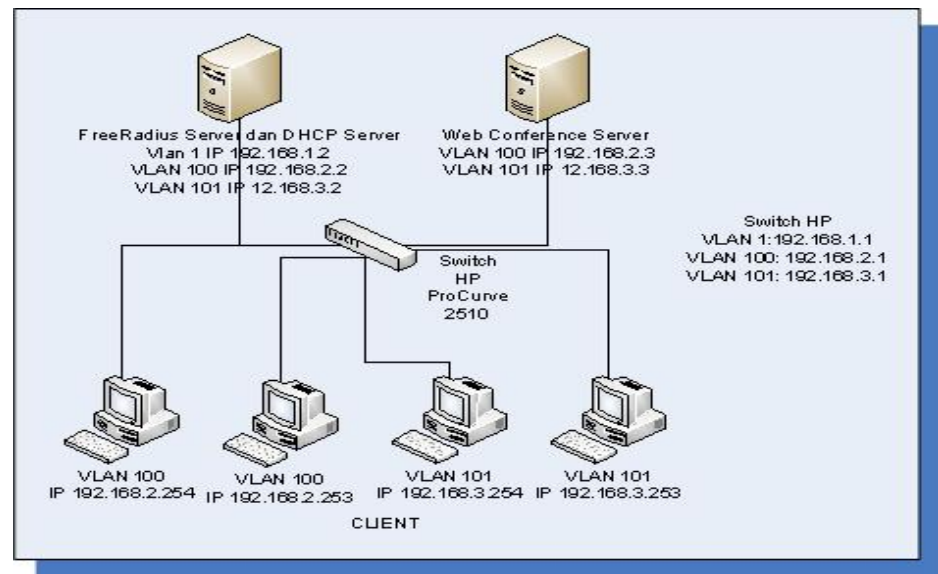

Gambar.5.Topologi jaringan tanpa sistem dinamik VLAN

Tabel.2. Hasil Pengukuran utilisasi Jaringan dengan sistem Dinamik VLAN

\begin{tabular}{|c|c|c|c|c|c|}
\hline & \multicolumn{5}{|c|}{ 4 Client } \\
\cline { 2 - 6 } & Web Server & Client 1 & Client 2 & Client 3 & Client 4 \\
\hline $\begin{array}{c}\text { Utilisasi Rata- } \\
\text { Rata (bits/s) }\end{array}$ & $2,359,200$ & $471,256.87$ & $436,366.96$ & $441,377.96$ & 424.905 \\
\hline & 192.168 .2 .3 & & & & \\
IP Address & 192.168 .3 .3 & 192.168 .2 .254 & 192.168 .3 .253 & 192.168 .3 .254 & 192.168 .2 .253 \\
\hline Durasi (men) & - & $1: 00$ & $1: 00$ & $1: 00$ & $1: 00$ \\
\hline
\end{tabular}

Dari pengukuran diatas didapatkan utilitas rata-rata dari webserver yang digunakan untuk web conference sebesar 2,36 Mbps dan utilisasi rata-rata client sebesar 440 kbps.

Tabel.3. Hasil Pengujian Web Conference di Jaringan Tanpa VLAN dan dengan VLAN dengan jumlah client sebanyak 4 buah

Tabel.3. Tabel Utilisasi Jaringan tanpa dan dengan Dinamik VLAN

\begin{tabular}{|c|c|c|c|c|}
\hline & \multicolumn{2}{|c|}{ tanpa VLAN } & \multicolumn{2}{c|}{ dengan VLAN } \\
\cline { 2 - 5 } & Web Server & Client & $\begin{array}{c}\text { Web } \\
\text { Server }\end{array}$ & Client \\
\hline $\begin{array}{c}\text { Utilisasi Rata-Rata } \\
\text { (bits/s) }\end{array}$ & 2.282 .400 & $674.376,04$ & 2.359 .200 & $443.476,72$ \\
\hline Durasi (menit) & - & $1: 00$ & - & $1: 00$ \\
\hline
\end{tabular}




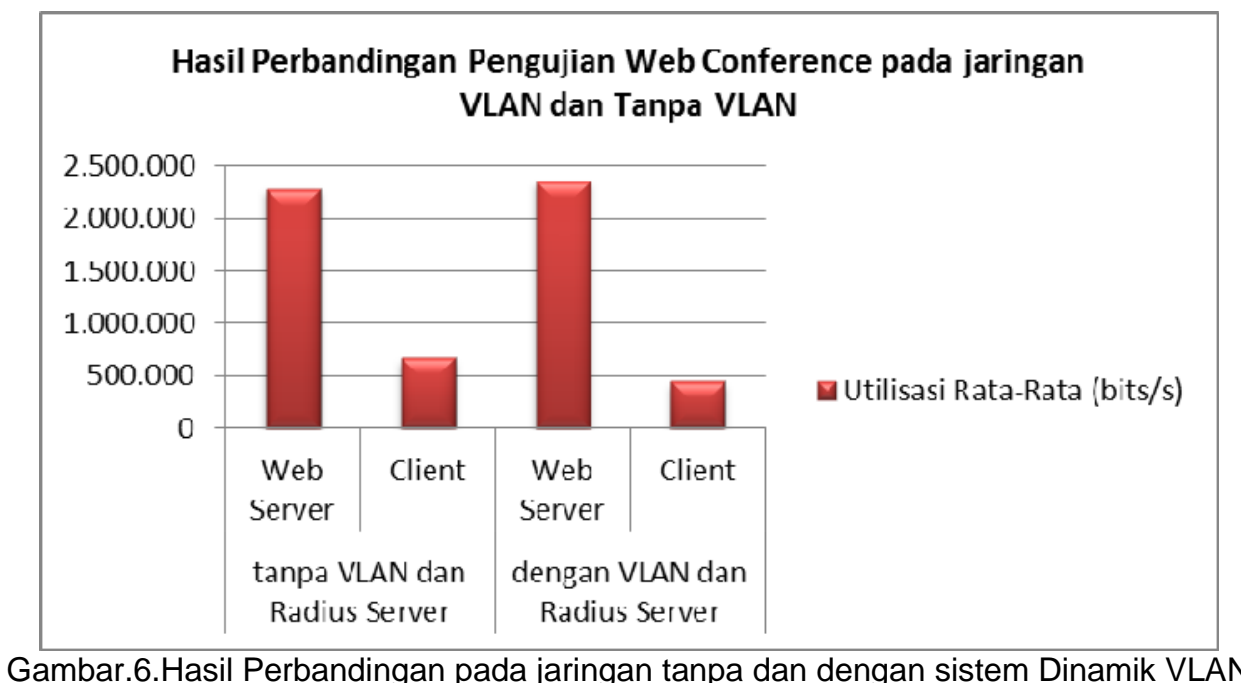

Dengan melakukan perbandingan antara jaringan tanpa dan dengan system pengalokasian dinamik VLAN, kita mendapatkan perbedaan yang kecil pada utilisasi jaringan rata-rata dari web server, yaitu sebesar 76,8 kbps dimana terjadi peningkatan sebesar 3,36\% jika dibandingkan dengan jaringan tanpa system pengalokasian dinamik VLAN.

Namun perbedaan yang sangat besar telihat pada utilisasi client, dimana terjadi penurunan sebesar 231,5 kbps jika dibandingkan dengan jaringan tanpa system pengalokasian dinamik VLAN. Namun perbedaan yang sangat besar ini bukan merupakan pengaruh dari penggunaan system pengalokasian dynamic VLAN, tetapi karena adanya perbedaan switch yang digunakan saat implementasi jaringan. Pada jaringan tanpa system pengalokasian dinamik VLAN digunakan unmanageable switch3Com dan pada jaringan dengan system dinamik VLAN digunakan manageable switchHP Procurve dimana pada spesifikasinya terdapat fitur packet compression.

\section{KESIMPULAN}

Berdasarkan hasil pengukuran dari penggunaan Sistem Dinamik VLAN dan aplikasi Web Conference, dapat disimpulkan bahwa Penggunaan sistem Dinamik VLAN tersebut tidak memberikan perbedaan yang sangat signifikan pada utilisasi jaringan. Pada pengujian, dapat dibandingkan utilisasi server Web Conference tanpa sistem dinamik VLAN sebesar 2.282.400 bps dan utilisasi server Web Conference dengan sistem dinamik VLAN sebesar 2,359,200 bps. Didapatkan bahwa terjadi peningkatan utilisasi sebesar 3,36 \%.

Dalam implementasi sistem ini, tidak memerlukan perubahan topologi jaringan secara besarbesaran dan digunakan aplikasi open source yang cukup handal untuk menjalankan aplikasi-aplikasi seperti halnya pada aplikasi berbayar.

\section{DAFTAR PUSTAKA}

1. Hassell,Jonathan. 2002, RADIUS Securing Public Access to Private Resources, Amerika Serikat: O'Reilly Media

2. Lammle, Tod. 2007, CCNA: Cisco Certified Network Associate Study Guide, Indiana Polis, Indiana, Amerika Serikat: Willey Publishing

3. Lo, Billion. 2009, Implementasi Sistem Dynamic Virtual Local Area Network untuk Aplikasi Web Confrence, Jakarta: Universitas Trisakti

4. Ramadhana, Yovira. 2008, Sistem Konferensi Video Berbasis Web dengan Menggunakan Aplikasi Open Source, Freeware dan Shareware, Jakarta: Universitas Trisakti 